\title{
Oralidad y cultura radicalizada en el interior de la provincia de Córdoba, Argentina. Los casos de San Francisco y Río Cuarto en las décadas de 1930 y 1940
}

\author{
Orality and radical culture in the province of Cordoba, Argentina. \\ The cases of Rio Cuarto and San Francisco in the 1930s and $1940 \mathrm{~s}$
}

\author{
Mariana Mastrángelo*
}

RESUMO

Este trabajo estudia la existencia de una cultura radical en la Argentina, fuera de los principales centros urbanos. Especialmente se estudian dos ciudades: San Francisco y Río Cuarto en la provincia de Córdoba, en las décadas de 1930 y 1940. El uso de la historia oral nos ayuda a descubrir un mundo rico desconocido para nosotros. Análisando una serie de entrevistas a los trabajadores, intelectuales y militantes políticos, encontramos una nueva concepción de la política, la cultura y la militancia. La mayoría de los entrevistados tienden a explicar su politización como natural derivación de su experiencia de vida y no como lo que percibimos como un tradicional proceso de politización.

PALAVRAS-CHAVE: Argentina; Política; Memória; Oralidad; Cultura.

\section{ABSTRACT}

This paper looks at the existence of a radical culture in Argentina, outside the main urban centers. Especially we study two cities: San Francisco and Río Cuarto in Córdoba province, in the 1930s and 1940s. The use of Oral History helps us discover a rich world unknown to us. Analyzing a series of interviews to workers, intellectuals and political militants, we found a new conception of politics, culture and militancy. Most of interviewees tend to explain their politicization as natural derivation of their life experience rather than as what we perceive as a traditional process of politicization.

KEYwORDS: Argentina; Politic; Memory; Orality; Culture.

Las historias personales y la "Historia”, esa que aparece en los libros y con mayúscula, siempre en algún punto se entrecruzan. Este entrecruzamiento entre historias personales y la historia como disciplina que pregunta, analiza y trata de buscar respuestas, es lo que hace que nuestra asignatura tenga sentido y sea significativa como un elemento de cambio. En este sentido, y en este entretejido de la historia y de las historias personales, la historia oral ha jugado un rol central como nexo entre ambas. Como herramienta metodológica, ha tendido puentes entre la memoria legítimamente producida por los historiadores y las memorias individuales, en lo que tienen de personal y colectivo (Apud BENADIBA y PLOTINSKY, 2005: 9). A partir de la definición de historia oral

\footnotetext{
* Doutoranda em História pela Universidad de Buenos Aires (UBA) / Argentina.
} 
como un intento por combinar el predominio de la narrativa con la búsqueda de conexión entre biografía e historia, entre experiencia individual y la transformación de la sociedad (PORTELLI, 1997), se intentará en este trabajo vincular las historias personales con una historia colectiva que marcó gran parte de la historia contemporánea argentina. Los testimonios escogidos para este artículo refieren a la experiencia de hombres y mujeres que han transcurrido a lo largo del siglo XX. Específicamente, nos interesa rastrear la existencia de una cultura radicalizada en dos ciudades de la provincia de Córdoba, como son el caso de la ciudad de San Francisco y de Río Cuarto, en las décadas de 1930 y 1940. Entendemos por cultura radicalizada, basándonos en la definición del autor inglés Raymond Williams, como "una descripción de una forma de vida particular, que expresa ciertos significados y valores no sólo en el arte y en el aprendizaje, sino también en instituciones y el comportamiento cotidiano" (1965: 57-70). Ese comportamiento cotidiano Williams lo denominó "comportamiento correcto", "sentido común" (1989). Para recuperar esa cultura radicalizada en el interior de la provincia de Córdoba, las vivencias de los entrevistados, vistas en conjunto, nos permitirán trazar los años formativos de la clase obrera, de la sindicalización y de la presencia de partidos de izquierda en ciudades del interior de la Argentina.

De los testimonios escogidos para este trabajo, las vivencias personales de los entrevistados pueden ser analizadas en su conjunto. El elemento central que tienen en común vincularía el lugar de procedencia de los entrevistados con sus prácticas políticas y culturales. Los entrevistados provienen de ciudades del interior del país y en general sus vidas han estado signadas por la militancia partidaria. Lo interesante de los testimonios en su conjunto es que la idea de lo que significa la política para los entrevistados se aleja de aquella mirada que la describe como una estructura meramente partidaria y de militancia orgánica. Para el autor inglés Raymond Williams (1980), existe una fuerte tradición socialista que conecta la práctica comunista con el partido. De esta manera, este tipo de interpretación ha influenciado gran parte de los trabajos sobre el tema. En cambio, lo que manifestarían los testimonios que se han seleccionado para este trabajo, es una visión más compleja y amplia de lo que entienden por política los entrevistados. Habría una naturalización de la política para los testimoniantes, casi sin darse cuenta, la misma estaba en el partido, en el 
gremio, en la actividad intelectual, en la vida diaria. Entonces. ¿Cómo interpretamos esta idea que tienen los entrevistados de la política? ¿Qué significa la política para estas personas? Sí no se mencionara que los mismos tenían tanto una militancia comunista como peronista, no podríamos distinguir posturas ideológicas. Un ejemplo de esto lo encontramos en el testimonio de Mariano Planells, ${ }^{1}$ ex intendente peronista por la ciudad de San Francisco: "nosotros sino hubieran surgido Perón y Eva Perón y quizás todos terminábamos con Bombas Molotov en la bandeja, claro seguro, seguro los chicos todos, porque se vivía amargamente". Este testimonio deja entrever algunos de los elementos que vienen mencionándose y que recorrerán todo este trabajo. Por un lado, la necesidad de la gente común de hacer algo frente a la explotación y la injusticia. La lucha de clases no puede ser considerada como un componente sólo del discurso marxista, sino que la misma atraviesa la vida de estas personas y las determina. A tal punto que su respuesta es el ingreso a la política. De esta manera, indistintamente, tanto el discurso popular del peronismo como la prédica radicalizada de los partidos de izquierda llevaron a generaciones de argentinos a participar en política. Estos interrogantes deberían sugerirnos que lo que impulsa la incorporación en la política de estos entrevistados se refiere más a prácticas culturales que vivenciaron en sus ciudades pequeñas que con nociones de índole política e ideológica. En este sentido, el historiador inglés Raphael Samuel es quien, a partir de su investigación sobre la militancia del Partido Comunista inglés (CPGB), nos sugirió repensar qué sucedía con las prácticas políticos-culturales en las ciudades chicas. Este autor, centrándose en la zona del East End de Londres (SAMUEL, 1985 y 1986), a través de testimonios, cartas, poemas, autobiografías y novelas logró reconstruir un rico mundo político y social asentado en una cantidad de tradiciones y expresiones culturales que mostraban un submundo izquierdista de una riqueza y vitalidad insospechada para la mayoría de los historiadores. El deslizamiento y la resignificación cultural de estas tradiciones en otras nuevas, él las llamó los "teatros de la memoria" (SAMUEL, 1994). Eran pautas y criterios izquierdistas que se vivían no como "política" o "ideología"

\footnotetext{
1 Mariano Planells fue intendente en la ciudad de San Francisco durante el período 1973-1976. Entrevista realizada por Alejandro Dugheti el 20 abril de 2000.
} 
sino como "comportamiento correcto", como "sentido común". ${ }^{2}$ Rastrear ese tipo de prácticas es el objetivo de este artículo. Por esta razón, los testimonios que siguen ha continuación han sido seleccionados ya que los entrevistados, en su conjunto, han contribuido a la formación tanto del Partido Comunista como del Partido Peronista, así como también a la constitución de los primeros sindicatos en las ciudades de San Francisco y de Río Cuarto. De sus testimonios se desprenden pautas izquierdistas que conforman un mundo desconocido hasta el momento.

Veamos el testimonio de Juan Floriani,3 escritor, miembro del Partido Comunista y responsable de la célula de zona "centro" de la ciudad de Río Cuarto, entre 1942 y 1972:

P: Don Juan, dígame cuándo y dónde nació usted.

R: Nací el 29 de octubre de 1924, en Río Cuarto.

P. ¿Y cuándo ingresa usted al Partido Comunista?

R: En el año '42.

P: ¿'Tenía dieciocho años?

R: Diecisiete y estaba terminando el secundario. $\mathrm{Y}$ en ese tiempo fui corresponsal de un diario del partido, el diario La Hora. En ese tiempo escribía, comunicaba para una revista de Buenos Aires, que por supuesto no tenía nada que ver con la izquierda. Entonces me solicitaron que me hiciera cargo de la corresponsalía del diario $\mathrm{La}$ Hora.

P: ¿Y por qué se mete en el Partido Comunista?

R: Porque tengo amigos, un muchacho adolescente del secundario que me empieza a traer material, comencé a leer y me interesó.

P: O sea que lo reclutaron, no es que se metió solo...

R: No me reclutó porque no era afiliado, él leía. Entonces yo también comencé a leer y me deslumbró. Leí a Lenin sobre Los Tres fundamentos del marxismo: la economía política inglesa, la filosofía alemana y el socialismo histórico francés. Eran los tres puntos sobre los cuales decía Lenin que surgía el marxismo.

P: ¿Y usted se afilió ahí?

R: No. Comencé primero por colaborar, independiente. Por ejemplo el hecho de aceptar ser corresponsal del periódico. Y después me afilié, primero a la Juventud Comunista y después al Partido.

Nótese en el testimonio anterior la necesidad del entrevistado de ser preciso en las respuestas, al extremo de detallar cómo ingresa a militar en el Partido Comunista. Esto contrastaría con la forma en que el entrevistado percibe la política. La presenta como algo natural, como "sentido correcto", “empecé a leer y me deslumbró". La incorporación a la militancia para el entrevistado, de esta manera, era lo que debía hacer y de forma natural, sin cuestionamientos, ingresó en la política y lo interesante es que ésta determinó

\footnotetext{
2 Muchos de estos planteos se basan en la sugerente obra de Raymond Williams, en particular, véase Resources of Hope. Culture, Democracy, Socialism (1989).

3 Entrevista a Juan Floriani realizadas por Pablo Pozzi y Mariana Mastrángelo, el 5 marzo de 2004.
} 
gran parte de su vida. En contraste, el siguiente testimonio también demuestra cómo la política estuvo presente en la vida del entrevistado. A diferencia del anterior, adviértase cómo el tema de la política incomoda y hasta avergüenza al testimoniante. La siguiente entrevista es de Ernesto Trigueros de Godoy,4 hijo del intendente por San Francisco, Serafín Trigueros de Godoy, quién fuera el fundador del partido vecinalista Comité Popular de Defensa Comunal, en las décadas de 1920, 1930. Trigueros de Godoy fue uno de los promotores de la importancia de la educación y de la salud pública, como también de la justa distribución de la riqueza en su ciudad.

\begin{abstract}
P: Ernesto, naciste en San Francisco ¿En qué año?
R: Bueno yo nací hace... en 1926.

P: ¿Cómo era tu infancia en San Francisco, te acordás?

$\mathrm{R}$ : Si, me acuerdo eh... muy marcada por la política, muy marcada por la política, papá era un hombre que decía que los políticos no tenían que tener familia, y lo practicaba, ¿̇no?

P: O sea...

R: Entonces, este... en la lucha política de esa época que era muy brava, que era muy dura, este... vos como chico percibís demasiado las cosas, percibís demasiado las cosas porque en algún sentido te sentís marginado de ciertos núcleos sociales, máxime en el caso de papá que era... no te puedo decir terminantemente que era de izquierda, pero era de izquierda. Y que... los este...

P: ¿Decías?

R: Bueno, te decía que yo no puedo decir que papá era de izquierda, pero papá era de izquierda políticamente sí, su forma de pensar sí, pero la gente que lo rodeaba, la gente que estaba con papá, políticamente lo apoyaba, etcétera, era un poco una mezcla de cosas. El amigo mayor que tenía papá era el Jefe de Asuntos Legales de la Municipalidad de San Francisco, el Dr. Fernando García Montagno, pertenecía a la más alta oligarquía cordobesa, el abuelo de Fernando García Montagno, tiene su estatua frente al Colegio Nacional de Montserrat, de la Universidad de Córdoba, así que fíjate el núcleo de eso. En contraposición, el abogado de papá en los juicios que tuvo, en los problemas políticos y que sé yo, y también su gran amigo, era Deodoro Roca5, yo no se si vos lo conoces a Roca...
\end{abstract}

En la entrevista anterior, por razones distintas, la política y "ser de izquierda” se convirtió en un problema para el entrevistado. La sensación que relata el entrevistado cuando era niño "de que mi infancia estuvo marcada por la política”, también "sentirse marginados de ciertos núcleos sociales porque papá era de izquierda”, dan cuenta de que la política formaba parte de la vida cotidiana de estas personas y la determinaba, pero en este caso, de manera negativa. Así, como en el otro caso la lectura de izquierda deslumbró al

4 Entrevista realizada a Ernesto Trigueros de Godoy por Mariana Mastrángelo el 27 de agosto de 2005 .

5 Abogado, periodista, docente y militante universitario, uno de los principales gestores de la Reforma Universitaria en 1918 en Córdoba. 
entrevistado y eso lo condujo a la militancia, en este último testimonio las ideas radicalizadas del padre significaron la vergüenza y la marginalidad del testimoniante. Por otro lado, como manifiesta el testimoniante, "la política era un poco una mezcla de cosas". Progresistas, radicales, conservadores y más tarde peronistas ${ }^{6}$ podían confluir en una misma alianza política. Esto daría cuenta de la complejidad y amplitud de cómo perciben el concepto de política los entrevistados. Más que compartimentos estancos, la ideología de cada partido podía trascender y configurarse en un "sentido común", en un "comportamiento correcto". Comentarios como "esa persona era comunista pero era buena gente" son frecuentes en los testimonios. O al decir los entrevistados sobre intendente Serafín Trigueros de Godoy:

\footnotetext{
Él representaba las clases... cuando no estaba el peronismo el representaba en ese momento a los sectores populares, tambien se decia "Trigueros de Godoy padre de los pobre, terror de los ricos" te das cuenta, esa, esa es la forma.... era un hombre bueno.7
}

O también, por ejemplo, cuando se le preguntó al mismo entrevistado si se acordaba de algún miembro del Partido Comunista ${ }^{8}$ en la ciudad de San Francisco, este recordaba:

\begin{abstract}
Había uno que era secretario general del Molino Río de la Plata, vos lo podes creer, si te parece bárbaro, Mangaterra, gerente general de los Molino Río de la Plata. Un hombre de bien, pero él seguía siendo el Gerente. Y el tipo cuando llegaba la revista del Partido Comunista que no me acuerdo cómo se llama, una revista que se editaba, creo que era la revista Así...él personalmente las llevaba y las colocaba en las peluquerías y los sectores en que se reunía la gente.
\end{abstract}

Estos fragmentos de los testimonios sugieren que cuando se denomina al militante comunista como un "hombre de bien", o al Intendente Trigueros de Godoy, como "un buen hombre”, “que representaba a las clases populares” se está definiendo a los mismos con criterios izquierdistas que darían cuenta de pautas culturales que tiene el entrevistado al momento de expresar sus puntos de vista sobre estas personas, más allá de si concordaba o no con sus tendencias ideológicas o políticas. No se lo identificaba en este caso al gerente del molino como un indeseable por ser comunista, sino que remarca que era una buena persona, y hasta el mismo entrevistado se sorprende que el gerente del molino

6 El Partido Radical, el Partido Demócrata, el Partido Peronista, el Partido Socialista y el Partido Comunista, este último ilegal, eran las fuerzas políticas de las décadas de 1930 y 1940.

7 Entrevista realizada a Mariano Planellls, al ex Intendente de San Francisco, por Alejandro Dugheti, el 20 abril de 2000.

8 Ibidem. 
más importante del país fuera comunista. Lo plantea como una paradoja, pero a la vez que estaba bien porque era una buena persona. Lo que sugerirían estas percepciones de los entrevistados sería un deslizamiento, de nociones políticas e ideológicas a pautas culturales que en este caso, se identifican con un "comportamiento correcto".

Otro de los testimonios que se han tomado como ejemplo es la entrevista a Raúl Piacenza,9 quién fuera diputado peronista por la ciudad de San Francisco en el período 1951 a 1955. En la entrevista se relata cómo el entrevistado ayudó a conformar el Sindicato de Empleados de Comercio. Nótese en la misma el protagonismo que ostenta el testimoniante y la carrera política que desarrolla. Es importante recalcar que con el advenimiento del peronismo, muchos obreros y empleados, a través de la militancia partidaria, cobran un protagonismo que era impensado en el período anterior. Por eso esta entrevista podría entenderse cómo una bisagra ya que introduce el cambio que se produce con la llegada de Perón al poder.
P: ¿Cuál es su nombre?
R: Raúl Leoncio Piacenza
P: ¿Cuándo empieza su trabajo político acá en San Francisco?
R: En San Francisco empiezo mi trabajo político a través del sindicalismo, es decir bien, no lo quiero engañar más o menos en el '45, en el '46, pero el trabajo gremial yo lo empecé en los primeros meses del ' 46.
P: ¿En esos años Usted participó de la conformación del Partido Laborista? ${ }^{10}$
R: Yo si, del Partido Laborista participé, pero participé políticamente en Córdoba, porque yo hasta el '45 viví un tiempo en Córdoba y ahí me relacioné con toda la gente laborista y de la Alianza Libertadora y porque yo vengo del nacionalismo, no.
P: ¿De la Alianza Nacionalista de Córdoba?
R: No, de la Unión Nacionalista Argentina de Oses, ${ }^{11}$ de Enrique P. Oses. Cuando yo vine acá traje la orden, o la indicación de que me metiera en los gremios y como yo vine a trabajar a una casa de comercio de San Francisco este... ingresé inmediatamente en el sindicato.
P: ¿Qué sindicato?
R: De Empleados de Comercio, entonces se usaba el Centro Empleados de Comercio más bien como un centro cultural, pero para

9 Entrevista realizada por Alejandro Dugheti el 10 de abril de 2000.

10 El Partido Laborista fue el producto de los sucesos del 17 de octubre de 1945, donde la clase obrera se movilizó en reclamo por la liberación del General Juan D. Perón. De esta iniciativa, el movimiento obrero sacó la conclusión que debía crear un partido obrero, el Partido Laborista. El mismo se mantuvo hasta las elecciones de 1946, en donde salió electo Perón, luego, por iniciativa de éste se disolvió y su lugar fue ocupado por el Partido Peronista.

11 Había dos alas nacionalistas. Estaba la Unión Nacionalista Argentina que era de Enrique P. Oses y estaba la Alianza Libertadora con el Dr. Blanco. La Unión Nacionalista Argentina tenía una clara orientación obrera y la Alianza Libertadora tenía inserción en la universidad y entre profesionales. 
nada de sindicalismo, de eso no se hablaba. Cuando entramos nosotros realizamos una asamblea grande, claro ya había sido el 17 de octubre, ${ }^{12}$ por supuesto que eso nos dio un gran envión y la existencia de gremios como La Fraternidad. El Ministerio de Trabajo y Previsión ${ }^{13}$ también nos ayudaba bastante. En Tampieri teníamos la ventaja de que los 300, 400 obreros que tenía la fábrica, estaban todos juntos,

P: ¿'Todos juntos?

R: Todos unidos. Empezamos a trabajar, se eligió una comisión provisoria, y me eligieron subsecretario y después a los tres meses se eligió la comisión general y me eligieron ya secretario general del gremio Empleados de Comercio del año 1946 hasta 1955. De 35, 36 empleados de comercio llegamos a ser 1.200 empleados, $1.200 \mathrm{y}$ entramos a agrupar, incluso, los pueblos vecinos.

El testimonio de Raúl Piacenza está atravesado por una nueva forma de hacer política con el ingreso del peronismo en la arena política. Ésta forma parte de la vida pero la coloca en un lugar central y fundante. El entrevistado tenía una orden del partido, la de conformar sindicatos, y a partir de allí, su protagonismo es fundamental en la constitución del Sindicato de Empleados de Comercio. Antes de que llegaran ellos, o sea los peronistas, "el Centro Empleados de Comercio se utilizaba como un centro cultural, de sindicalismo no se hablaba"... "empezamos a trabajar con 35 afiliados y terminamos siendo 1.200, y entramos a agrupar a los pueblos vecinos”. El entrevistado estaría marcando un antes y un después, desconociendo y borrando el trabajo previo de comunistas y socialistas en la conformación de los sindicatos ya existentes en la ciudad de San Francisco. Reconoce a La Fraternidad, sindicato de los maquinistas ferroviarios en donde convergían socialistas, comunistas y anarcosindicalistas, pero este era uno de los gremios más importantes del país, imposible no reconocerlo. Pero su testimonio desconoce que el Sindicato de Oficios Varios, creado a raíz de la huelga de 1929, denominada "Tampierazo", fue obra de los comunistas. O que éstos, junto al Partido Vecinalista Comité de Defensa Popular, liderado por Trigueros de Godoy, fueran los promotores de las primeras escuelas de oficios para pobres, de la creación de hospitales públicos, de los primeros sindicatos, bibliotecas y centros culturales en San Francisco. Es interesante ver cómo el discurso obrero y popular del peronismo se alimentó de

12 El 17 de octubre de 1945 es un día emblemático para los peronistas ya que ese día toda la clase obrera se movilizó por la liberación del General Juan D. Perón.

13 Se refiere a la Secretaría de Trabajo y Previsión que fue creada durante el gobierno militar del general Farrell. A cargo de la misma estaba Juan D. Perón. La nueva secretaría tendió a establecer una relación más fluida con el movimiento obrero, sancionándose una serie de reformas en la legislación laboral. 
toda una rica tradición izquierdista y la amoldó a sus objetivos, y esto queda claro en el testimonio antes citado. Son los peronistas quienes descubren a las clases populares, es el 17 de octubre el despertar de la clase obrera. Así, toda una cultura radical que venía gestándose desde fines del siglo XIX y principios del siglo XX en el país, y en este caso, en ciudades pequeñas del interior como pueden ser San Francisco o Río Cuarto, es reinterpretada y lo curioso es que son muchos los obreros, socialistas y comunistas que se incorporan en las filas del peronismo. Un caso paradigmático es el del intendente con ideas izquierdistas (como lo define su hijo Ernesto) Serafín Trigueros de Godoy. Él fue uno de los fundadores del Partido Peronista en Córdoba. Su hijo nos relata como ingresa su padre al partido:

\begin{abstract}
Papá fue fundador del Partido Peronista en Córdoba. El Partido Peronista en Córdoba se funda en la quinta del [nombre ininteligible], y ahí estuvo papá presente, y estuvo el abogado este que yo te decía Fernando García Montagno que también es fundador del Partido Peronista en Córdoba. En esa época, al principio Perón, y si, representaba la defensa de las clases obreras, de las clases pobres, se podía decir que era realmente la izquierda de la política Argentina. Entonces se forma el Partido Peronista que era el defensor de las clases pobres, el defensor de los obreros, ahí se empiezan a sacar las primeras leyes sociales. ${ }^{14}$
\end{abstract}

Es importante remarcar cómo el testimonio anterior resume toda una percepción de la época y cómo la historiografía sobre el tema ha contribuido a este tipo de interpretación. ${ }^{15}$ La irrupción del peronismo marcó un antes y un después en la historia política contemporánea argentina, haciendo suyo pautas y criterios izquierdistas. La pregunta aquí sería por qué se ingresa al peronismo y los que en esa época optan por un partido de izquierda, cuales son las razones de dicha elección. El siguiente testimonio es extenso pero es una síntesis de la complejidad del contexto histórico del cual estamos haciendo mención. La entrevista es a Víctor Barrios, ${ }^{16}$ obrero de la construcción, miembro del Partido Comunista y secretario del Gremio de la Construcción en la ciudad de Río Cuarto.

P: Don Víctor, hablando de distintas cosas, usted menciona que ingresa al Partido Comunista en 1946, ¿Por qué ingresa al Partido Comunista?, ¿̇por qué no a otro lado?

R: Yo ingreso al Partido Comunista de la mano de un hermano mayor

14 Entrevista realizada a Ernesto Trigueros de Godoy por Mariana Mastrángelo el 27 de agosto de 2005 .

$15 \mathrm{Al}$ respecto véase la rica discusión en torno a los orígenes del peronismo.

16 Entrevista realizada a Víctor Barrios por Pablo Pozzi el 26 de agosto de 2006. 
mío, cuando regreso de Buenos Aires, después de estar casi cuatro años en la Capital, ingreso el mismo día que se vota para presidente de la nación a Perón, el veintiséis de febrero de 1946. Yo regreso a casa, a la casa de mis viejos, ehm... inmediatamente mi hermano me lleva prácticamente de la mano a la sede del Partido Comunista que estaba en la calle Cabrera, acá en... esquina Deán Funes, y me da toda la letra por qué no hay que votarle a Perón.

P: ¿A Perón?

R: Yo en ese tiempo no tenía ninguna... inquietud -digamos asípolítica ni ideológica. Había mamado sí, en Buenos Aires, mucha... mucha práctica con el peronismo, porque estaba trabajando en una heladería, que era en la calle, en la Avenida de Mayo, donde había un grupo numeroso de trabajadores, aproximadamente cien, y la mayoría era gente del peronismo, yo creo que todos. El único que no adhería al peronismo en ese tiempo era yo.

P: ¿Pero usted no adhería por cabezón o por alguna otra cosa específica? Porque debe haber sentido mucha presión en contra de eso.

R: Sí es indudable que sentía mucha presión. Es decir, la discusión del peronismo ahí era muy... muy al día, estaba constantemente, cuando se hablaba de algo era hablar del peronismo. Pero aparte de la, digamos así, de lo que hablábamos de nuestras raíces como gente del interior, gente que veníamos perseguidos por el hambre a Buenos Aires, porque no encontrábamos trabajo en la Capital, entonces se hablaba mucho, pero yo no adhería al peronismo y eso que marchamos juntos el 17 de octubre, aquella famosa marcha, que empezó en el Congreso, se deslizó por Entre Ríos, o para el Sur, que es... para el Norte, digo para... hasta Córdoba, creo que fue, y de ahí a la 9 de Julio y culmina en la Plaza de Mayo.

P: ¿Y por qué marchó el 17 de octubre Usted?

R: Bueno, yo marché porque me sentía atraído por la cantidad de gente del interior que había. Es decir los "cabecita negra", que le llamaban en aquel tiempo a los que íbamos del interior, nos habíamos juntado todos. Es decir, parecía que éramos del mismo color, los negritos del interior que los señalábamos como cabecitas, nos sentíamos atraídos por la proclama, por el llamado que hacía Perón a los trabajadores.

P: ¿Y sin embargo usted no se hizo peronista y, por qué no?

R: Yo no me hice peronista porque... la verdad tenía mucha desconfianza de Perón en si por ser un militar. Y no se, será porque yo desde chico no tenía mucha simpatía con los milicos, que le decíamos en ese tiempo, en la zona rural que vivíamos en San Luis, generalmente a la policía o a los militares, le teníamos cierta alergia, es decir, eran los que reprimían a los campesinos cuando se rebelaban, o porque les faltaba el respeto a alguno o no lo saludaban, los metían presos, los reprimían y toda la gente que nos rodeaba cuando éramos muy chicos, le tenían una aprensión así a la... a la investidura de la... al uniforme, ya sea policíaco o militar. Y tenía cierta desconfianza en el mensaje, porque todos los que rodeaban a Perón eran gente rica, en los cuales nosotros habíamos desde chicos habíamos sufrido las consecuencias. Entonces un poco de desconfianza, y eso quizá hizo que... lo padecí en Río Cuarto también, antes de irme a Buenos Aires, acá mis hermanos, por ejemplo, los llevaron presos de la plaza porque estaban sentados y los llevaron por vagancia.

P: ¿A su hermano?

R: A mi hermano en la década más o menos del '40. '38, '40, que eran jóvenes y estaban desocupados, la plaza se llenaba de desocupados y los llevaban presos, los reprimían en vez de ayudarles a... Entonces tenía una aversión a... muy pronunciada contra la autoridad en sí. $\mathrm{Y}$ para mi Perón era autoridad, era uniforme.

P: ¿Y su hermano cuando se hizo comunista? 
R: Mi hermano se hizo comunista acá, por vinculación con socialistas y comunistas, él era sastre...

P: ¿Acá en Río Cuarto?

R: En Río Cuarto, después de... como es... de mucho tiempo de trabajar en el campo, el aprendió el oficio era un buen sastre, y se vinculó con los Cedriani, con alguna otra...con Dalmaso que era un empleado de comercio, con el PC, con los que trabajaban en el gremio de la construcción, mi hermano tuvo vinculación a través de los amigos socialistas y del Partido Comunista. Entonces por eso el me inculcó lo que era el comunismo en pocas palabras, indudablemente yo no entendía mucho la cosa, pero ya tenía esa rebeldía contra el poder, es decir contra los poderosos.

El testimonio de Barrios es una síntesis del contexto en el cual el peronismo irrumpe en la escena política y se mezcla con todo un submundo izquierdista. Así como en el testimonio de Raúl Piacenza queda claro que el entrevistado no tenía ninguna duda sobre porqué se hizo peronista y sindicalista en la ciudad de San Francisco, para Víctor Barrios, en cambio, el peronismo le inspiró desde el comienzo desconfianza, porque Perón era militar y significaba la autoridad que durante años había reprimido a su gente en su San Luis natal. También Perón estaba rodeado de los mismos ricos que habían explotado a él y a su familia sin piedad. Como el entrevistado remarca en su relato, él de política o ideología mucho no entendía cuando ingresa a militar. Ni qué hablar de marxismo. Pero si hay una vida marcada por la explotación y el hambre. El concepto de experiencia de Edward P. Thompson ${ }^{17}$ es significativo para el caso de Barrios y de los anteriores entrevistados, cuyas experiencias de clase lo impulsan a militar en un partido de izquierda en un contexto en donde la gente que lo rodeaba, "los cabecitas negras del interior", todos en general se hicieron peronistas. Es fundamental preguntarse porqué este obrero de la construcción, que también ayudó a conformar el gremio de la construcción en Río Cuarto se hizo comunista y no peronista. ¿Qué razones impulsaron a estas personas a sumarse al comunismo, un partido que estaba en la clandestinidad en las décadas de 1930 y 1940? ¿Cómo eran estos pueblos o ciudades chicas del interior del país? ¿Había obreros urbanos o rurales en estos lugares? ¿Partidos de izquierda?

\footnotetext{
17 Este concepto de experiencia lo tomamos de Edward. P. Thompson. Este autor plantea que: "las personas se encuentran en una sociedad estructurada en modos determinados, que pueden ser relaciones de producción, experimentan la explotación (o la necesidad de mantener el poder sobre los explotados), identifican puntos de interés antagónico, comienzan a luchar por estas cuestiones y en el proceso de lucha se descubren como clase, y llegan a conocer este descubrimiento como conciencia de clase. La clase y la conciencia son siempre las últimas y no las primeras fases del proceso real histórico" (1989).
} 
Cuando revisamos los periódicos de la época y los censos industriales y de población encontramos que estos pueblos o ciudades chicas del interior cordobés tuvieron una fuerte incidencia en la estructura económica y social de la provincia y del país. En este sentido, los testimonios deben ser interpretados no como casos aislados sino que estarían dando cuenta de un contexto en donde esas pautas izquierdistas de las cuales venimos haciendo mención, pueden generalizarse de las ciudades chicas a la ciudad capital de Córdoba.

Partiendo de los datos empíricos, los censos de 1895 y $1914^{18}$ demuestran que la industria argentina se hallaba fuertemente concentrada en pocos centros, particularmente en el entorno del Gran Buenos Aires. Esas concentraciones industriales en torno a unos pocos centros urbanos, y en general ubicados sobre el eje La Plata-Buenos Aires-Litoral cercano, comienzan en la década de 1930 y se acentúan en los años 1950 y 1960. Para el resto del país se verifica una gran heterogeneidad por estratos ocupacionales y tipo de actividad. Por ejemplo, en 1895 la Capital Federal concentraba unas dos terceras partes de la producción, masa laboral y fuerza motriz, el resto del país, incluyendo Córdoba y Santa Fe quedaban muy rezagados con respecto a este. En 1914, ese panorama cambia a favor de una distribución regional más equilibrada, pero dentro de un marco de industrialización incipiente (DORFMAN, 1983). Para el caso de Córdoba, el Censo Industrial de $1935^{19}$ registra sólo en la ciudad capital 984 establecimientos industriales, con un total de 10.460 entre obreros y empleados contratados. La ciudad de Río Cuarto tenía 175 establecimientos 777 obreros y la ciudad de San Francisco 68 establecimientos y casi 1.000 obreros. Estas cifras aumentan un 40\% en el Censo Industrial de $1939 .^{20}$ Estos datos indicarían un crecimiento industrial con una concentración obrera importante en las décadas de 1930 y 1940.

Los cambios producidos en la ciudad de Córdoba en 1870 a raíz de la instalación del ferrocarril, el incremento del comercio y de la construcción provocaron un aumento del $2,4 \%$ en el sector secundario, mostrando un claro crecimiento del sector industrial. ${ }^{21}$. Esto produjo cambios sustantivos a partir de

\footnotetext{
18 Véase censos de 1895 y 1924 en lo que respecta a la industrialización.

19 Censo Industrial de 1935. Tomo I.

20 Censo Industrial de 1939. Tomo I.

21 Estos datos pueden observarse en el Censo Municipal del año 1906. Véase el Instituto de Estudios Americanistas de la Universidad Nacional de Córdoba.
} 
1870-1914 para las autoras Hilda Iparraguirre y Ofelia Pianetto (1968) en la estructura productiva ya que la misma se amplió en su base social, empezando a aparecer un importante número de artesanos urbanos, pequeños productores rurales y suburbanos y obreros asalariados.

Estos ejemplos demuestran que si bien había una industrialización incipiente, esta existía y albergaba a un importante porcentaje de obreros. Esto se complejizaría si tomamos en cuenta las memorias de Jesús Manzanelli. Este dirigente obrero comunista señalaba que el movimiento obrero cordobés era tan importante y combativo que para la década de 1920 y 1930, más de cuarenta sindicatos ingresaron en la nueva central del proletariado cordobés, ${ }^{22}$ reuniendo a más de cincuenta mil obreros entre la ciudad y el campo. Quizás esta cifra esta sobredimensionada, puesto que de ser cierta, se puede inferir que Córdoba sería una de las provincias con más trabajadores organizados en el país. Sin embargo, más allá de su estricta veracidad, la misma refleja la importancia que tenía el movimiento obrero en esta ciudad y particularmente en esa época la Unión Obrera Provincial (UOP) que estaba en manos del Partido Comunista. Para rastrear esta tradición organizativa y política del movimiento obrero cordobés hay que remarcar que ya en 1870-1880 surgen las primeras organizaciones mutualistas de trabajadores y, en 1890, se empiezan a organizar los primeros sindicatos por oficio en la ciudad (los primeros serán los telégrafos y correos, siguiéndole los panaderos y los ferroviarios). También es de destacar que en 1874 se conforma una sección de La Primera Internacional y, en 1890, se inaugura el Club Vörwarts, festejándose en esta ciudad el primer aniversario del Día del Trabajador (HIPARRAGUIRRE y PIANETTO, 1968).

La necesidad de organización de los obreros en la UOP y previamente en sindicatos se debía, a su vez, a que el nivel de conflictividad en esta provincia fue una de sus características más sobresalientes desde las primeras décadas del siglo XX.23 Los años 1920 y 1930 estuvieron signados por altos niveles de conflictividad, tanto en la provincia como en la misma capital de Córdoba. Los

\footnotetext{
22 En bastardilla ya que la frase es tomada de Jesús Manzanelli (1971: 17). La Unión Obrera Provincial fue constituida en 1919.

23 La primera huelga que se registra en la ciudad de Córdoba es en 1888, siendo los empleados del correo los primeros en reclamar aumento de sueldo. De allí en adelante, tipógrafos, foguistas, panaderos, peones italianos, etc., se ven envueltos en situaciones de resistencia contra la patronal.
} 
conflictos de obreros rurales en el interior de la provincia, 24 la repercusión de la huelga ferroviaria del año 1917,25 el Tampierazo en 1929 en San Francisco y, por sobre todas las cosas, la Reforma Universitaria en el año 1918 dan cuenta de este fenómeno. Esta última inauguró un proceso de cuestionamientos a nivel universitario que rápidamente tuvo repercusión en el movimiento obrero cordobés (FERRERO, 1999). A principios de 1918, la huelga de los obreros del calzado inició la marcha a un conjunto de huelgas que abarcarían varios gremios, entre ellos a Zapateros, Albañiles, Pintores, Carpinteros, Caleros y Molineros, los que en su gran mayoría triunfaron. En 1918, estos sindicatos se agruparon en la Federación Obrera Local (FOL) en la ciudad de Córdoba. Al mismo tiempo, en el sur y oeste de la provincia agraria, los obreros rurales entraron en pleno período de agitación. Delegados de la FOL incidían en pueblos y ciudades importantes como Marcos Juárez, Bell Ville, Villa María, Leones, Río Cuarto. En el término de un mes la ola de huelgas se había extendido por toda la zona agraria, organizándose más de veinte sindicatos, entre ellos, Estibadores, Carreros y Oficios Varios. ${ }^{26}$ En este ambiente de gran agitación, en 1919, se realizó el Congreso Constitutivo de la Federación Obrera Provincial (FOP).

Estos datos dan cuenta de una rica tradición obrera e izquierdista que viene gestándose desde fines del siglo XIX, tanto en la ciudad capital como en las ciudades del interior cordobés. Para el caso de la ciudad de San Francisco, en 1929, se desató una de las huelgas más sangrientas y violentas de la época. Este hecho quedó registrado en los diarios de la época, 27 tanto a nivel local como provincial ya que esta ciudad estuvo parada por tres meses y fue intervenida por el gobierno provincial. Nicolás Repetto, ${ }^{28}$ diputado socialista de la época, mencionaba la existencia de un soviet en esta ciudad. ¿No es extraño que hubiera obreros sino también partidos de izquierda en una ciudad del interior cordobés?

\footnotetext{
24 Sobre conflictos obreros-rurales, véase: Waldo Ansaldi (1993).

25 Véase para el tema de la huelga ferroviaria en Córdoba: Mónica Gordillo (1988).

26 Sobre conflictos obreros-rurales, véase: Waldo Ansaldi (1993).

27 El diario local La Voz de San Justo lleva una crónica minuciosa de la huelga de 1929 en esta ciudad. Los diarios La Voz del Interior y los Principios de la ciudad de Córdoba le dedican las páginas centrales durante varias semanas.
}

28 Minuta presentada por Nicolás Repetto. Diario de Sesiones de la Cámara de Diputados. 
Veamos que nos dicen los protagonistas de la época. A raíz de la huelga de 1929 en la ciudad de San Francisco entrevistamos a una de las participantes ${ }^{29}$ de la misma y esto nos decía:

P: Doña Leticia, ¿¿Usted participó en la huelga del año 1929?

R: No sé, cosas de juventud, como las compañeras... porque ahí había dos secciones, la sección mía se hicieron huelguistas, yo también me hice huelguista. Casi me mataron, porque ví morir a dos. La policía nos tiroteo una mañana que salimos en manifestación, ví morir a dos muchachos y una chica.

P: ¿A Rosa Venegas?

R: No me acuerdo más los nombres de ellos.

P: Ella es una de las que murió, tenía 14 años de edad.

R: Claro, si yo entré de 14 años en la fábrica.

$\mathrm{P}: \dot{\mathrm{Y} Y}$ en que sección trabajaba usted?

R: En la de paquete, había tres secciones y yo estaba en esa.

P: ¿Y cuánta gente trabajaba allí?

R: Se calculaba 300 personas.

El testimonio de esta participante en la huelga de 1929 no sólo revela el nivel de conflictividad de la época sino también refleja la cantidad estimativa de obreros que trabajaban en la fábrica Tampieri, lugar en donde este conflicto tuvo más eco. En otra entrevista a un obrero de la misma fábrica, descubrimos a su vez una gran variedad de industrias para la época. Este obrero ingresó a trabajar en la década de 1940, y nos decía:

P: En la década de 1940, ¿Cuántos obreros habrá habido acá en San Francisco?, ¿Se acuerda?

R: No, no podría acordarme de cuantos obreros había aquí en San Francisco

P: ¿Y recuerda cuantas fabricas había?

C: Tampieri tenía: fideos, galletitas, molino, transporte; el Molino Río de La Plata, el molino Boero, Miretti, Magnano y la fundición, que se yo y todas las fabricas que había por ahí, otras no me acuerdo, estaba Puzzi que estaba acá en la provincia de Santa Fe, que pertenecía a San Francisco, porque vivía él acá, pobre el trabajo que hacia era todo trabajo para San Francisco. ${ }^{30}$

Otro de los testimonios, pero en este caso de un obrero que entró a la fábrica Tampieri en el año 1944, en los años previos al peronismo, revela la cantidad estimativa de obreros que había en esa época en la fábrica:

P: Dígame Don Scavino ¿Por qué la mayoría de los obreros en la fábrica Tampieri eran mujeres?

$\mathrm{R}$ : Y porque era mucho trabajo de mujeres, la rosca, que hacia la rosca, o sea que tres mujeres hacían ocho bolsas a la mañana de 70 kilos y nueve a la tarde en rosca, tres mujeres nueve horas, había mas o menos 80 mujeres en la rosca, después cuando la señora Gregoria tocaba el pito y no salías se armaba una... y porque si salías y dejabas el trabajo y te hacia echar... había 4, 5 secciones había 460 mujeres y

29 Entrevista a Leticia Castelli por Mariana Mastrángelo, el 8 de octubre de 2001.

3o Entrevista a Cayetano Bonfiglioni, obrero de la fábrica Tampieri, realizada por Alejandro Dugheti el 15 de octubre de 2001. 
200 hombres cuando yo entre en el año 1944.

P: ¿En el año 1944 había más o menos 700 obreros en su fábrica?

R: Y más o menos... Cuando salí en el año 1977 había solo 25, ya estaba ido, ya estaba casi todo ido... ${ }^{11}$

Los distintos testimonios antes citados demuestran un importante desarrollo industrial ya para las décadas de 1930 y 1940. Sin embargo, en la ciudad de San Francisco, desde 1890 encontramos una incipiente industrialización que estaba ligada, sobre todo, a la economía agropecuaria de la época. Una de las primeras industrias que evolucionó en la zona fue una calera que respondía al rápido crecimiento de la construcción en la ciudad. Otra fábrica que comenzó en esos años a funcionar fue la de fideos Tampieri, Biava y Cía. En 1920, la fábrica, que funcionaba sólo con el nombre de Tampieri, contaba con un plantel de 150 operarios, en su mayoría, inmigrantes italianos, polacos, rusos, yugoslavos aunque también empleaba criollos.

En la misma década comenzó su actividad industrial, una fábrica de zarandas para máquinas agrícolas y otra fábrica de sulkis. A estas industrias se sumaron talleres de herrería y reparación de maquinarias agrícolas, talleres de curtiembre, una fábrica de jabones, otra de calzado, una carpintería mecánica, un taller de metalurgia, una fábrica de hielo y gaseosas.

Estos datos dan cuenta, por un lado, que la industria fue uno de los pilares de desarrollo económico en la ciudad de San Francisco, en donde la variedad de industrias y el número de obreros ${ }^{32}$ era importante. Por el otro lado, la huelga de 1929, que involucró a tres de las fábricas más importantes de la ciudad como fueron Miretti, Boero y Tampieri, puso en evidencia a un movimiento obrero que se organizó, politizó y movilizó por una lucha que comenzó como una reivindicación por la jornada de ocho horas y un aumento salarial y terminó politizando a estos trabajadores ya que su reclamo se orientó, gracias a la ayuda del Partido Comunista, hacia el reconocimiento del sindicato. La magnitud de la huelga puede indagarse tanto en los periódicos de la época que llevan una crónica minuciosa de la huelga, en donde por ejemplo, citan movilizaciones de obreros que sumaban entre 1.000 y 1.500 manifestantes recorriendo el centro de la ciudad.33 Puede también apreciarse a partir de la movilización que hizo la

31 Entrevista a Dionisio Scavino, obrero de la fábrica Tampieri, realizada por Alejandro Dugheti el 15 de octubre de 2001.

32 Véase los Censos Industriales de 1935, 1937 y 1939.

33 Véase La Voz de San Justo de los meses que van de junio a diciembre de 1929. 
Unión Obrero Provincial mandando a sus dirigentes más importantes de la época, como fueron los hermanos Manzanelli y Antonio Maruenda a organizar al movimiento obrero sanfrancisquense. Estos dirigentes, a su vez, eran importantes cuadros del Partido Comunista ya que la central obrera cordobesa en este período estaba en manos de este partido. Por último cabe remarcar que con esta huelga surgen los primeros sindicatos en la ciudad de San Francisco y de esta manera se fue conformando una experiencia (thompson, 1989) de clase que hizo que, por un lado se generaran redes solidarias entre los mismos obreros y, por el otro lado, que muchos de estos trabajadores llegaran a politizarse, sobre todo en el caso de las obreras de la fábrica Tampieri que conformaron la Asociación Feminista Comunista de San Francisco y la Juventud del Partido Comunista.

El otro ejemplo es la ciudad de Río Cuarto. En esta ciudad, la industria tuvo un rol secundario ya que las actividades agropecuarias eran el pilar de desarrollo económico. Sin embargo, la industria de la construcción absorbió a la mayoría de la mano de obra, junto a algunos talleres metalúrgicos, molinos de harina y las cosechas temporarias. Para las décadas de 1930 y 1940, según el censo de la Federación Departamental de Trabajadores, existían ya las siguientes organizaciones obreras. Centro Empleados de Comercio, Sindicato Único de la Construcción, Centro Femenino, Unión Obreros Municipales, Sindicato de Molineros y Anexos, Sindicato de Estibadores, Gráficos, Canillitas, Metalúrgico, Ladrilleros, etc. En cuanto a las zonas se explica la cantidad de organizaciones que surgieron en este período. Se mencionan los sindicatos rurales de Alejandro, Elena, Coronel Baigorria, Adela María, General Cabrera, Berrotarán, Alcira Gigena y casi todos los pueblos de la región sur. La Federación contabilizaba en el año 1937 a 2.568 trabajadores nucleados en su seno (BARRIOS, 2000). En el año 1935 se conformó la Federación Obrera Local (FOL), el dirigente del Sindicato de la Construcción, José Cagnetta, militante del Partido Comunista fue quien, bajo las órdenes de la UOP, lo organizó. Estos datos demostrarían, nuevamente, en otra ciudad del interior de Córdoba, la existencia de un porcentaje importante de obreros, así como también la presencia del Partido Comunista como organizador de este movimiento obrero y sindical.

El testimonio de Juan Floriani nuevamente es ilustrativo para comprender 
Mariana Mastrángelo

Oralidad y cultura radicalizada en el interior de la provincia de Córdoba, Argentina...

\section{cómo era la sociedad de Río Cuarto en las décadas de 1930 y 1940:}

P: Don Juan, ¿Y cómo era Río Cuarto cuando usted era chico?

R: Una ciudad pequeña, básicamente de clase media, ítalo-española, con una colectividad árabe y una colectividad judía también. Lo que caracteriza a la ciudad es su clase media. Por supuesto que en la parte urbana principal, porque en los alrededores está la gente pobre, sobre todo en siete oficios. Porque, como esta no es ni ha sido nunca una ciudad industrial, acá el obrero se las ha tenido que rebuscar de cosas distintas.

P: ¿Pero había obreros acá? ¿En qué trabajaban?

R: Sí que había, por supuesto. Eran de la construcción. Había dos importantes molinos harineros, uno Deminco y el otro Fénix, que ahora de nuevo ha comenzado a funcionar y ese era el núcleo industrial. Lo demás era el sieteoficio. Hacían más que nada la construcción. Muchos se iban para la cosecha, recolección de maíz.

P: ¿Era una ciudad muy conservadora, muy católica?

R: En general era una ciudad conservadora. Ahora, digamos, tenía influencia la Iglesia, por supuesto, era un 95\% la población católica. Pero no era un sector de intransigencia, no era una ciudad clerical. Era católica como era el argentino. Ese catolicismo más o menos liberal. Y había un pequeño sector judío que desde hace muchos años forma parte, también una pequeña colectividad japonesa, pero los japoneses que estaban acá eran católicos.

P: ¿El radicalismo tenía mucho peso?

R: Sí, sí, el radicalismo era muy fuerte, hasta que llega el peronismo ha sido una ciudad radical básicamente. Inclusive teníamos el contrapunto entre Córdoba y Río Cuarto. En Córdoba estaban los Sabattini y acá estaban los Zavala Ortiz. Entre ellos, el que después fue canciller. Esto quiere decir que inclusive teníamos un polo radical que tenía autonomía, en cierta medida.

P: ¿Y había izquierda, había anarquistas, socialistas?

R: Sí, izquierda socialista, anarquista y comunista.

P: Cuénteme un poco de cada uno, primero de anarquistas...

R: Anarquistas hubo siempre, pero de una forma inorgánica, como son los anarquistas, verdad. Tenían incluso dirigentes, los estibadores estaban dirigidos por anarquistas. Después había socialistas, que tenían su núcleo, incluso todavía tienen su local y su biblioteca, una biblioteca muy interesante.

P: ¿Cómo se llama la biblioteca?

R: Evaristo Segat, que era un dirigente de los socialistas de los comienzos.

P: ¿Los anarquistas también tenían centro cultural?

R: No. Yo por lo menos no conozco un local anarquista. Sí me acuerdo que tenían dirigentes en estibadores. Los socialistas eran más débiles en sindicatos. Tenían artesanos, el sindicato de los sastres, por ejemplo.

P: ¿Y había gente que adhería al anarquismo y al socialismo? ¿Mucha, poca?

R: Sí. El socialismo tenía un local, que sigue siendo el mismo hasta la fecha. Y el Partido Comunista, que se constituyó acá más o menos por el '3o, tenía influencia en la parte sindical, tenían empleados de comercio, en marineros, tenían mucha fuerza en construcción y los ladrilleros. Inclusive Banda Norte, que era donde estaban fundamentalmente los ladrilleros, le llamaban la pequeña Rusia. Incluso cuando hacían huelga los ladrilleros cortaban el puente e interrumpían la comunicación entre los dos sectores. Era un gremio muy combativo. Y en los gremios de la construcción eran muy fuertes los comunistas.

P: ¿Estamos hablando de la década de 1930?

R: 1930 y 1940, hasta que llega el peronismo. (BARRIOS, 2000). 
El testimonio de Víctor Barrios completa el relato anterior.

P: Don Víctor, ¿Cuántos militantes comunistas había aquí en Río Cuarto en los años previos al peronismo?

R: Quizás no tenía un gran peso en general, pero la verdad es que había un gran número de cuadros políticos en el movimiento obrero, en la construcción, en gastronómicos, en metalúrgicos, en molineros, empleados de comercio.

$\mathrm{P}$ : ¿̇A nivel de dirección o de base?

R: A nivel de dirección y de base. Todos eran militantes, líderes comunistas y dirigentes obreros de gran peso como Pulmonares, Flores, Cagnetta, quienes habían ayudado a la formación de las primeras organizaciones obreras y federaciones acá en la zona.

P: Y cuando gana Perón en el '46, ¿Qué pasa con esta gente?, ¿Pierden el control de los sindicatos?

R: Indudablemente yo creo que mucha gente que apoyó al Partido Comunista con su voto en el '46, muchos de ellos se fueron [sic] al peronismo, se hicieron peronistas... (BARRIOS, 2000).

$\mathrm{Si}$ entrecruzamos todos los testimonios antes analizados, en donde la naturalización de la política puede ser interpretada como "comportamiento correcto" o "sentido común" con esta serie de datos empíricos, vemos como emerge toda una rica tradición izquierdista en estos pueblos chicos. La realidad nos muestra a obreros, organización sindical y participación de partidos de izquierda como componentes de una sociedad atravesada por elementos conservadores, como cita uno de los testimoniantes por un lado, y de una cultura radicalizada que se manifestaba de distintas maneras. Una de ellas era a partir de organismos culturales, ya que cada partido de izquierda tenía su biblioteca o centro cultural. También lo hacían a través de la organización gremial. Ésta fue promovida por el Partido Comunista, que tendió a crear y a organizar a los primeros sindicatos de la provincia. Los dirigentes comunistas de la época tuvieron la ardua tarea de promover la necesidad de agremiarse, formando grupos de discusión, organizando a los jóvenes a través de la Juventud Comunista, a las obreras en Asociaciones Feministas y a los obreros/as en los primeros sindicatos de la época. Esta rica tradición izquierdista debe ligarse y entenderse junto al concepto de experiencia de Edward P. Thompson (1989). Las personas que pudieron ser entrevistadas tenían naturalizada la idea de política, para los mismos, militar en un partido de izquierda no era lo mismo que hacerlo en un partido tradicional. Como ellos mismos manifestaban, de política o ideología no entendían mucho, pero sí de explotación y tenían claramente identificado quién era el enemigo. Es precisamente en el fogueo de la lucha de clases, como plantea Thompson, que 
las personas van tomando conciencia de clase y esto puede verse en los testimonios. En su mayoría, los entrevistados se politizan y, ha excepción del testimonio de Juan Floriani que había tenido lecturas previas sobre marxismo, el resto de los entrevistados no tenían más que la convicción de que había que hacer algo y, en ese contexto, la política era el medio indicado, ya fuera militando en el Partido Peronista o en el Partido Comunista.

Para trazar y descubrir esta tradición izquierdista, la Historia Oral ha jugado un rol fundamental ya que a través de los testimonios recogidos y las fuentes escritas que se han consultado, se ha podido reconstruir todo un submundo que era desconocido hasta ahora.

También deben mencionarse los problemas propios que se plantean en el momento en que entrevistador y entrevistado se encuentran. Partimos de la idea que la Historia Oral es un tipo de fuente más que debe ser interpretada y analizada con las mismas precauciones que una fuente escrita. Como plantea Alessandro Portelli en La orden ya fue ejecutada (2004: 26 y 27) "la historia oral distingue entre hechos y relatos, entre historia y memoria, justamente porque considera que los relatos y las memorias son ellos mismos hechos históricos". Es la tarea del historiador hacer su trabajo tanto en la dimensión fáctica como en la narrativa, entre pasado y presente. $Y$ de esta manera es que se ha intentado analizar los relatos de nuestros entrevistados. Esta claro que uno de los inconvenientes más recurrentes que se presentaron fue el de la memoria, sobre todo si se tiene en cuenta que los entrevistados eran personas mayores de 70, 80 y hasta 90 años, como es el caso de las participantes en la huelga de 1929. En este sentido, es importante remarcar aquí lo que Alessandro Portelli planteara en otro de sus libros, en La muerte de Luigi Trastulli y otras historias. 34 Cuando este autor quiso entrevistar a la secretaria del anarcosindicalismo de la ciudad de Terni, esta mujer contaba con 93 años, lo que hizo imposible la entrevista, no sólo por cuestiones propias de la memoria, sino porque estaba débil físicamente. El problema aquí, como apunta este autor, no es sólo la memoria de la secretaria, sino que en muchos de estos casos la culpa es de los historiadores que por distintas razones dejan pasar a estas personas y sus historias quedan sin ser contadas. En el caso de nuestras entrevistas, las personas mezclaban la memoria con el mito y a su vez a esto se le interponía el

34 Véase: Alessandro Portelli (1991). 
olvido. De aquí se pueden derivar algunas reflexiones sobre estas problemáticas. Por un lado, el uso del mito así como su elaboración, son fenómenos que ocurren siempre desde el presente, en el momento en que se realizan las entrevistas y al calor de ellas. De ahí que se resignifiquen y acomoden a partir de las reflexiones que van haciendo los testimoniantes en diálogo con el entrevistador. Ambos construyen y reedifican el mito en la entrevista puesto que es un proceso que se construye entre dos. Resulta imposible dejar a un costado los a priori que lleva el entrevistador. El contenido de las entrevistas no busca reflejar toda la confiabilidad de la memoria sino que ésta va siendo moldeada por la situación del informante en el presente cuando se realiza la misma. No se trata de una cuestión de honestidad del protagonista. De ahí que no sólo proporcionan información sino que también transmiten creatividad, iniciativas colectivas, experiencia de vida, percepciones a través de metáforas y de figuras y formas de pensar. Todos estos elementos en conjunto constituyen una cultura determinada, como es el caso específico de la huelga del año 1929 en la ciudad de San Francisco35 y la constitución de los primeros sindicatos en la ciudad de Río Cuarto. Algo similar sucedió con las entrevistas que se realizaron a los militantes del Partido Comunista de Río Cuarto. La omisión y la sobredimensión de la información que brindaban fue una constante, producto de una práctica militante de años. Es por ello que el análisis posterior de las fuentes orales debe ser parte del ejercicio que debe realizar el historiador, al igual que con las fuentes escritas ya que el elemento subjetivo esta presente en ambos tipos de fuentes.

\section{Bibliografia}

ANSALDI, Waldo (comp.). Conflictos obreros rurales pampeanos. (1900-1937). Buenos Aires: Centro Editor de América Latina, 1993.

BARRIOS, Victor. Rescate a los pioneros. Río Cuarto: Universidad Nacional de Río Cuarto, 2000.

BENADIBA, Laura y PLOTINSKY, Daniel. De entrevistadores y relatos de vida. Introducción a la Historia Oral. Buenos Aires: Facultad de Filosofía y Letras. Universidad de Buenos Aires/Imago Mundi, 2005.

DORFMAN, Adolfo, Cincuenta años de industrialización en la Argentina,

35 Estas reflexiones son producto de discusiones que surgieron sobre el tema con el Profesor Pablo Pozzi. 
1930-1980. Buenos Aires: Ediciones Solar, 1983.

FERRERO, Roberto A.. Historia crítica del movimiento estudiantil de Córdoba. (1918-1943). Córdoba: Ed. Alción, 1999.

GORDILLO, Mónica. El movimiento obrero ferroviario desde el interior del país (1916-1922). Buenos Aires: Centro Editor de América Latina, 1988.

IPARRAGUIRRE, Hilda y PIANETTO, Ofelia. La organización de la clase obrera en Córdoba, 1870-1895. Córdoba: Universidad Nacional de Córdoba, 1968.

MANZANELLI, Jesús. La vida de un dirigente obrero y comunista cordobés. Buenos Aires: Centro de Estudios Marxistas-Leninistas "Victorio Codovilla", 1971.

PORTELLI, Alessandro. La orden ya fue ejecutada. Roma, las Fosas Ardeatínas, la Memoria. Buenos Aires: Fondo de Cultura Económica. 2004.

. The Battle of Valle Giulia. Oral History and the art of dialogue. Madison.: The University of Wisconsin Press, 1997.

. The death of Luigi Trastulli and other stories. Form and Meaning in Oral History. New York: State University of New York Press, 1991.

SAMUEL, Raphael. The Lost World of British Communism. New Left Review, $\mathrm{n}^{0} 154$, November-December 1985.

. The Lost World of British Communism: Two Texts. New Left Review $\mathrm{n}^{\mathrm{0}}$ 155, January-February 1986. El texto completo de la investigación fue publicado en 1988 como The Lost World of British Communism.

. Theaters of Memory. 2 vols. London: Verso Books, 1994.

THOMPSON, Edward P. Tradición, revuelta y consciencia de clase. Estudios sobre la crisis de la sociedad preindustrial. Tercera Edición. Barcelona: Editorial Crítica, 1989.

WILLIAMS, Raymond. Problems in materialism and culture. London: Verso Books. 1980

Books, 1989.

Resources of Hope. Culture, Democracy, Socialism. London: Verso

. The Long Revolution. Harmondsworth: Penguin, 1965.

Colaboração recebida em 14/12/2008 e aprovada em 15/03/2009. 